\title{
Contribuciones del derecho y el psicoanálisis sobre la memoria y el olvido en el postconflicto colombiano*
}

\author{
Judith Elena García Manjarrés** \\ Leonardo Rafael Mass Torres***
}

\author{
Recibido: 18 de enero de 2016 \\ Evaluado: 10 de marzo de 2016 \\ Aceptado: 1 de abril de 2016
}

\section{Resumen}

El postconflicto colombiano ocupa el interés del Derecho y de la Ciencia Política, entre otros, por su indiscutible trascendencia, quienes han buscado explicaciones al mismo basándose en las regularizaciones que permite la Ley, como la denominada Justicia Transicional, dentro del marco del Derecho Internacional Humanitario y los Derechos Humanos. Esto ha adquirido un compromiso con el lugar que ocupan la memoria y el olvido para la reparación del conflicto armado: el legado de una memoria social que permita a sus protagonistas poder significar de un modo diferente los estragos de la guerra. Ahora bien, se propone que la memoria y el olvido son funciones que también trascienden el marco legal y jurídico, en tanto integran la vida psíquica del sujeto. Es por esto que el psicoanálisis, como disciplina que atiende la singularidad que define a cada sujeto en la clínica, puede comprender el impacto que en la subjetividad ha tenido el conflicto armado. Para lo anterior, se realizó una atenta revisión teórica y conceptual desde el campo del Derecho y el Psicoanálisis sobre las relaciones que la memoria y el olvido guardan con las leyes jurídicas y

\footnotetext{
El presente artículo de reflexión es producto de la investigación Verdad, perdón, olvido y reparación: Lugares posibles para un sujeto en el postconflicto armado colombiano. Esta investigación está adscrita al grupo Sanus Viventium del Subsistema de Investigación Institucional (SIDI) de la Universidad Metropolitana de Barranquilla. DOl: http://dx.doi. org/10.15332/s1794-3841.2017.0027.02

** Magíster en Psiconeuropsiquiatría y Rehabilitación, Universidad Metropolitana. Especialista en Psicología Clínica, Universidad Metropolitana. Psicóloga, Universidad Metropolitana. Investigadora del Grupo Sanus Viventium, Universidad Metropolitana. Barranquilla, Colombia. Correo: judithelena16@ unimetro.edu.co Código Postal: 080020.

*** Candidato a Dr. En Psicoanálisis, Universidad Andrés Bello (Chile). Magister en Psicología, Universidad del Norte. Especialista en Psicología Clínica, Universidad Metropolitana. Psicólogo, Universidad Metropolitana. Investigador del Grupo CEPUM, Universidad Metropolitana. Barranquilla. Correo: leonardomass@unimetro.edu.co Colombia. Código Postal: 080020
} 
la vida psíquica: si para el Derecho la memoria se propone como un derecho primordial amparado por la Ley, el Psicoanálisis, por su parte, promueve que el sujeto puede hacerse responsable con su memoria de aquello que ha olvidado subjetivamente.

Palabras claves: Postconflicto, Derecho, Psicoanálisis, Memoria, Olvido, Sujeto 


\section{Law and psychoanalysis contributions about the memory and oblivion of the Colombian Postconflict}

Received: January 18, 2016

Evaluated: March 10, 2016

Accepted: April 1, 2016

\section{Abstract}

The Colombian postconflict is studied by Law and Politics due to its indisputable importance. These academies, have searched for answers about it by using the Transitional Justice within the International Human Right and the Human Rights. This has acquired a commitment with the Memory and Oblivion in the repair of the Army Conflict: The legacy of a social memory that allows the protagonists view the consequences of the war in a different way. From that perspective, the memory and oblivion are functions that also impact the legal and judicial framework since they are part of the psyche of the subjects involved. This is the reason why, the Psychoanalysis as a discipline that studies the singularity of an individual, can understand the impact these functions can have on the subjectivity of a person that experienced the army conflict. In order to attain this, a rhetorical and conceptual revision of the Law and Psychoanalysis in relation to the Memory and Oblivion was performed to encounter the applicable principles from each discipline. On one end, The Law proposes Oblivion as a primary protected right; on the other end, Psychoanalysis promotes that the subject can be held accountable with his/her memory of what has been subjectively forgotten.

Key Words: Post-conflict, Law, Psychoanalysis, Memory, Oblivion, Subject 


\section{Contribuições do direito e a psicanálise sobre a memória e o esquecimento no pós-conflito colombiano}

\begin{abstract}
O pós-conflito colombiano ocupa o interesse do Direito e da Ciência Política, entre outros, por sua indiscutível transcendência, quem tem buscado explicações para ele baseando-se nas regularizações que permite a Lei, como a denominada Justiça Transicional, dentro do marco do Direito Internacional Humanitário e os Direitos Humanos. Isto tem adquirido um compromisso com o lugar que ocupam a memória e o esquecimento para a reparação do conflito armado: o legado de uma memória social que permita aos seus protagonistas poder significar de um modo diferente aos estragos da guerra.
\end{abstract}

Agora se propõe que a memória e o esquecimento são funções que também transcendem o marco legal e jurídico, enquanto integram a vida psíquica do sujeito. Por isso a psicanálise, como disciplina que se ocupa da singularidade que define a cada sujeito na clínica, pode compreender o impacto que na subjetividade tem tido o conflito armado. Para isso, realizou-se uma atenta revisão teórica e conceitual desde o âmbito do Direito e da Psicanálise sobre as relações que a memória e o esquecimento têm com as leis jurídicas e a vida psíquica: se para o Direito, a memória propõe-se como um direito primordial amparado pela Lei, a Psicanálise, por sua parte, promove que o sujeito possa se fazer responsável com a sua memória de aquilo que tem esquecido subjetivamente.

Key Words: Pós-conflito, Direto, Psicanálise, memória, esquecimento, sujeito.
Recebido: 18 de janeiro de 2016

Avaliado: 10 de março de 2016

Aceito: 1 de april de 2016 


\section{INTRODUCCIÓN}

A partir de la búsqueda de la disolución del conflicto armado interno colombiano, por parte del Gobierno del presidente Juan Manuel Santos (2010-2018) y las Fuerzas Armadas Revolucionarias de Colombia (FARC), así como su continuación con los Diálogos de Paz que se llevaron a cabo en la La Habana, Cuba (en septiembre de 2012), en la que intervinieron ambas partes, a saber, tanto delegados del Gobierno como representantes de las FARC, se propuso como meta la consecución de un acuerdo viable para las dos partes, que posibilite la obtención de la paz en Colombia y que esté mediado por las propuestas de que la verdad acerca de los actos violentos cometidos dentro del conflicto sea dicha y conocida por la población civil y por el sistema legal, para que emerjan así la justicia, la reparación y haya derecho, para aquellos que han delinquido, a la reinserción a la vida civil, siempre que sea preservada del olvido la memoria colectiva (Ley 975, Congreso de la República de Colombia, 2005). Así, las posibilidades frente al postconflicto colombiano y su viabilidad han interesado a disciplinas como el Derecho y la Ciencia Política que, intentando encontrar propuestas que se enmarquen en la Ley, han formulado nuevos proyectos para judicializar a los actores del conflicto.

Estos proyectos de Ley que emergen dentro de la llamada Justicia Transicional pretenden lograr justicia promoviendo no sólo el acceso a la verdad de los hechos, sino también la reinserción a la vida civil de quienes han delinquido dentro del conflicto y la reconciliación de los mismos con la población civil, preservando la memoria colectiva del olvido (Ley 975, Congreso de la República de Colombia, 2005). Esta Justicia
Transicional es propuesta por Uprimny y Saffon (2005) como aquella que:

Hace referencia a un problema muy antiguo, relativo a qué debe hacer una sociedad frente al legado de graves atentados contra la dignidad humana, cuando sale de una guerra civil o de un régimen tiránico. ¿Debe castigar a los responsables? ¿Debe olvidar esos atropellos para favorecer la reconciliación? (p. 214).

Lo anterior quiere decir que pensar el postconflicto en Colombia implica necesariamente hacerlo bajo los parámetros de la Justicia Transicional; esa que ha cobrado importancia a partir de los estragos dejados por la violencia vivida en la Primera Guerra Mundial (Teitel, 2003) y que emerge como pilar de la reconstrucción de la historia y la judicialización de los hechos violentos para la posible reparación de los mismos en una nación (Laplante y Theidon, 2008). De esta reparación se espera que haga posible remediar los actos violentos cometidos anteriormente y que permita que, por el acuerdo entre partes, a saber, Gobierno y alzados en armas, no se repitan las violaciones contra los Derechos Humanos. Hablar de Justicia Transicional implica, entonces, en el caso de Colombia, asumir que se está "viviendo realmente una transición, esto es una superación del conflicto armado" (Uprimny y Saffon, 2005).

Esta transición implicaría reconocer que se ha estado en guerra, que es esa guerra la que se pretende cesar y que a partir de ese reconocimiento puede ser posible la emergencia de unos parámetros de justicia que respeten unos estándares que se inscriben en el marco del Derecho Internacional Humanitario y, 
a su vez, dentro de los Derechos Humanos. Sin embargo, en Colombia, este reconocimiento sobre la vivencia de la guerra y los estragos que ella ha causado han tenido sus propios matices, y ha logrado que la Justicia Transicional sea un tema que desde 1997 preocupa y ocupa al Gobierno de turno (Ley 418, Congreso de la República de Colombia, 1997). Este generalmente se ha interesado en promover nuevas políticas que puedan dar paso no sólo al diálogo con los grupos armados, sino también a las propuestas de saber la verdad acerca de los actos violentos y lograr el perdón de los mismos por parte de las víctimas y la población civil para, posteriormente, tratar de preservar la memoria colectiva, procurando que haya derecho después al olvido y que pueda abrirse paso a la reparación del daño causado a las víctimas por parte de quienes cometieron los actos violentos (Ley 975, Congreso de la República de Colombia, 2005).

En 1997, se propuso en Colombia la Ley 418, que propendía por un intento de negociación con la guerrilla como grupo armado al margen de la Ley. Esta Ley fue prorrogada más tarde por la Ley 782 de 2002 que, a diferencia de la anterior, contemplaba y buscaba la desmovilización de los grupos paramilitares a los que en ese momento se les dio el carácter para su juzgamiento como delincuentes políticos; esto fue reafirmado con la Ley 975 de 2005 conocida como la Ley de Justicia y Paz (Congreso de la República de Colombia, 2005). En ella, se establecían las formas para que los paramilitares que entraran en los diferentes procesos de Ley fueran juzgados dentro de un marco de Justicia Transicional y, a su vez, este marco también se proponía como el escenario para que las víctimas pudieran recibir su derecho a la reparación por los actos ilícitos padecidos. Sin embargo, a la mirada de algunos, esta última ley tampoco ponía sus ojos sobre las víctimas, sino que, por el contrario, aparecía como aquella que reclamaba derecho para los victimarios. Así, "la Ley de Justicia y Paz no rompe con la tradición" (González, 2005, p. 52) y su estructura finalmente, "no permitía la obtención de justicia, verdad y reparación" (Morris, González, Morelo \& Palencia 2015, p. 499).

Con el panorama de críticas a las leyes que se postularon en 1997 y 2005, surge en el 2011 la Ley 1448, conocida también como la Ley de Víctimas, que intenta, dentro de un marco de Justicia Transicional, promover escenarios para que a las víctimas se les

posibilite hacer efectivo el goce de sus derechos a la verdad, la justicia y la reparación con garantía de no repetición, de modo que se reconozca su condición de víctimas y se dignifique a través de la materialización de sus derechos constitucionales (Congreso de la República de Colombia, 2011).

Lo anterior implica entonces la emergencia de las siguientes preguntas: ¿qué posibilidades de reparación y no repetición pueden ocurrir, toda vez que estos hechos violentos, así como su intento por la no repetición y la reparación de los mismos, si bien atañen a conceptos legales, también parten del lugar del sujeto? ¿De qué memoria se trata? Para el interés de este abordaje, es pertinente que dichas preguntas, no solo se acojan al marco del Derecho, sino además, tener presente los referentes con que el Psicoanálisis ha contribuido al campo de la subjetividad, en tanto allí se trata de un sujeto distintivo que habla y actúa acorde al lenguaje que le estructura 
de manera psíquica: el sujeto tiende a repetir y a sentir que algo no va conforme como él lo espera conscientemente.

Así, puede encontrarse que el Psicoanálisis tampoco ha sido ajeno al estudio sobre temas de la violencia y los efectos de la misma en el ser humano. Sigmund Freud escribió en su texto titulado El malestar en la cultura (1929), acerca de las formas como el sujeto, al estar inmerso en la cultura debe renunciar a sus exigencias pulsionales que piden su satisfacción y, si bien por el lazo social es posible hacer esa renuncia, también algo de sus exigencias quedan. Ese resto psíquico que no puede ser satisfecho es el que produce malestar, lo que le permite afirmar que el hombre es "un ser entre cuyas disposiciones pulsionales también debe incluirse una buena porción de agresividad" (Freud, 1929, p. 3046) y esa agresividad del sujeto generalmente está dirigida al otro, que no sería

únicamente un posible colaborador y objeto sexual, sino también un motivo de tentación para satisfacer en él su agresividad, para explotar su capacidad de trabajo sin retribuirla, para aprovecharlo sexualmente sin su consentimiento, para apoderarse de sus bienes, para humillarlo, para ocasionarle sufrimientos, martirizarlo y matarlo (Freud, 1929, p. 3046).

Lo anterior, implica reconocer que el Psicoanálisis, desde su nacimiento, se ha ocupado de realizar una lectura de la cultura, pues es en ésta donde está inmerso el sujeto de su interés, que, a su vez, como lo propone el Psicoanálisis, está gobernado por el inconsciente, que es el responsable no sólo de cómo actúa y habla dicho sujeto, sino también de aquello que olvida, repite y de lo que guarda en la memoria. Eso que olvida un sujeto, que tiene para el Psicoanálisis un lugar privilegiado, está en juego también en el escenario del postconflicto armado colombiano. Si bien, el Psicoanálisis no concibe el sujeto sin la posibilidad de que este pueda olvidar - pues, tal como afirma Freud (1895): “toda teoría psicológica digna de alguna consideración habrá de ofrecer una explicación de la memoria" (p. 214)-no se trataría, en ningún caso, de cualquier forma de olvido, menos aun cuando éste atañe a los estragos sufridos por la guerra, como es el caso del conflicto armado colombiano.

En consecuencia, en este artículo se verá de qué manera la concepción de memoria y su correlato, el olvido, tal como se proponen dentro de las condiciones del postconflicto armado colombiano, atañen tanto al Derecho como al Psicoanálisis. El primero lo plantea en relación con los hechos violentos, como aquello contra lo que hay que luchar a través de la preservación de la memoria y también como un derecho al que, después de un tiempo, aquellos que han delinquido pueden acceder. El segundo se ocupa de memoria y olvido como algo de lo que el sujeto no puede escapar, aunque crea que ello es posible conscientemente; tal como sostiene Freud (1901): "no hemos olvidado todo lo que creíamos" (p. 928).

De esta manera, puede decirse que tanto el Derecho como el Psicoanálisis se ocupan del asunto de la memoria y el olvido desde lugares particulares. Así, si el uno los defiende dentro del marco de la Ley, el otro los propone como inherentes y necesarios para la estructuración psíquica del ser humano. En conclusión, se trata de reflexionar, con base en los conceptos de memoria y olvido 
que promueve la ciencia jurídica para el postconflicto, sobre aquello contra lo que se lucha y también sobre aquello a lo que hay derecho pasado un tiempo, así como sobre las relaciones críticas que pudiesen establecerse en función del estatuto que comporta el sujeto del Psicoanálisis, sujeto que olvida, reprime y recuerda.

\section{Memoria y Olvido en Derecho}

A partir de las guerras mundiales, la noción de memoria ha adquirido un carácter relevante en torno a las discusiones sobre hechos violentos, justicia y logros de paz que realizan historiadores, políticos, filósofos, sociólogos y profesionales de las ciencias jurídicas. El asunto de preservar del olvido los hechos violentos y conceptualizar la memoria para superar los estragos y la repetición de la violencia ha sido punto de anclaje para naciones que padecieron durante algún tiempo la vivencia del conflicto armado.

Colombia, como nación sufriente de un conflicto armado con una historia de más de cincuenta años, no ha sido ajeno a la temática de la memoria y el olvido. En el proceso de desmovilización de los grupos armados y las conversaciones que se llevan a cabo en La Habana, así como en medio de la Justicia Transicional que ha emergido como escenario para judicializar los actos violentos del conflicto armado interno, el Gobierno y sus comisionados se han ocupado de pensar las propuestas para alcanzar la paz y con ello lo ateniente a la memoria y el olvido de los hechos y efectos que ha dejado el conflicto armado interno colombiano.
Estas discusiones sobre memoria y olvido han encontrado su punto de anclaje y desarrollo no sólo en el retorno hacia el pasado histórico en algunas naciones, sino también, y principalmente, en las transiciones políticas de aquellos países que han sufrido guerras internas. Sin embargo, en casos como el colombiano, la discusión puede adquirir otro matiz, toda vez que, si bien se están adelantando negociaciones y diálogos con el propósito de alcanzar el fin del conflicto, este último sigue presente y aún no pertenece al pasado, sus luchas y efectos se siguen viviendo día tras día. Pese a ello, por iniciativa del Gobierno Colombiano, se han venido adelantando iniciativas que propenden por la preservación de la memoria histórica. Sin embargo, frente a estas iniciativas, vale la pena pensar que, toda vez que dentro de la Justicia Transicional el asunto de la memoria es visto como un derecho que exige la población y que va acorde no sólo con la posibilidad de no repetición de los hechos, sino que representa la posibilidad del olvido, ¿cómo construir y/o reconstruir entonces la memoria histórica con fines de evitar la repetición?

Así, dentro del marco de lo jurídico y transicional se inscribe el Derecho a la Memoria como parte de un intento por resolver un conflicto armado, que no sólo lleva varios lustros, sino que es protagonista de múltiples violaciones a los Derechos Humanos, como en el caso de Colombia. A partir de allí, la Ley propone que frente a la demanda de justicia y reparación, se ponga en marcha un sistema que propenda por la reconstrucción del tejido social, en el que prime el derecho a conocer la verdad sobre los hechos y que los daños sufridos como efectos sean reparados, toda vez que se busca la garantía 
de la no repetición por medio de la reconstrucción de lo que se denomina memoria histórica. Esta memoria, para constituirse como es propuesta, debe inscribirse en un contexto político:

En efecto, este tipo de norma será más eficaz en la medida en que su adopción interviene en un tiempo lo más cercano posible a los hechos que son su objeto, y en la medida en que el proceso de la memoria se inscribe dentro de un proceso político de establecimiento de la protección de los derechos, gracias a una clarificación y a una reparación de los sucesos en los cuales se basa el proceso de memoria. Su objeto no es entonces simplemente conmemorativo y retributivo; estableciendo oficialmente los hechos en su verdad, y presentando esta verdad como indiscutible, sino de manera más compleja y dinámica, se trata de enlazar una sentencia oficial sobre los hechos a una acción política para el futuro (Millard, E., 2004, p.146).

Esta sentencia que pone en juego la verdad, ubica el Derecho de la Memoria en relación con la reparación, con el fin de asegurar que no se repitan los daños en el futuro. Esto toca directamente a los Derechos Humanos y ha sido pensado por la Corte Interamericana de Derechos, quienes proponen que los Estados o naciones deben implementar acciones en pro no sólo de la preservación de la memoria histórica, sino de la preservación de la memoria de las víctimas. La primera está más en relación con la no repetición de los hechos, mientras que la segunda estaría más ligada a la reparación posible de los daños. Sin embargo, aunque ambos derechos parecen pretender fines distintos, no van en contravía: en algún momento pueden coincidir o una misma medida permite alcanzar ambos fines. De esto, dice Rincón: "el derecho a la memoria no colapsa en la pretensión de no repetición ni, por lo tanto, en las llamadas garantías de no repetición" (Rincón, 2010, p. 10).

La Corte Interamericana de Derechos, reconoce y propone esta diferencia en el caso Anzualdo Castro Vs Perú (Corte Interamericana de Derechos Humanos, 2009), en el que propone la creación del Museo de Memoria. Sin embargo, este centro de Memoria, aunque propende por la reconstrucción de los hechos y la memoria histórica, parece dejar de lado el asunto de la memoria de las víctimas. Por ello, la misma CIDH consideró posteriormente medidas que cobijan la preservación de la memoria individual de las víctimas, que antes no había sido considerada. Dice la CIDH:

La propuesta del Estado de sustituir el acto de reconocimiento por el "Museo de la Memoria" no constituye una medida individual de satisfacción adecuada, si bien el Tribunal reconoce que ese tipo de iniciativas son significativas en atención a la recuperación y construcción de la memoria histórica de una sociedad. En razón de lo anterior, la Corte considera necesario que el Estado realice un acto público de reconocimiento de responsabilidad por la desaparición forzada de Kenneth Ney Anzualdo Castro, y de desagravio para él y sus familiares, en particular por el tratamiento que se les dio desde su desaparición. Este acto deberá realizarse en su presencia y, en lo posible, con el acuerdo y cooperación de 
los familiares, si es su voluntad. El acto deberá contar con la participación de altas autoridades del Estado y celebrado dentro de un plazo de seis meses, contado a partir de la notificación de la presente Sentencia, y las autoridades procurarán la mayor difusión posible en los medios de comunicación (CIDH, 2009, párrafo 200).

Lo anterior quiere decir que, aunque las medidas estatales puedan tomarse para la construcción de la memoria histórica, esta no necesariamente significa o va en la misma vía que el Derecho a la Memoria individual de las víctimas. La primera no satisface la segunda, toda vez que ésta última se trata de una experiencia que atañe directamente al sujeto y a la vivencia de este con respecto al hecho violento. Es decir, el Derecho a la Memoria implica necesariamente al sujeto, pues opera estructuralmente sobre él. Sobre esto, que no ocurre sin dificultades, afirma Pablo De Greiff: "la víctima no pierde su condición de fin en sí misma y no es instrumentalizada para favorecer, a futuro, la no repetición" (2005, p. 219). Es por ello que, en Colombia, lo que se propone como Derecho a la Memoria, no sólo encuentra su sustento en los hechos violentos, sino también en el relato de la vivencia de uno y cada uno de aquellos, que a partir de esos hechos violentos emergen como víctimas. No puede pensarse entonces el Derecho a la Memoria sin recorrer los caminos de la subjetividad.

Así, el 20 de agosto del 2010, se propone el Derecho a la Memoria por primera vez como estatuto en la Ley 1408. Este estatuto rinde homenaje a las víctimas y propone para ello no sólo los dispositivos para localizar e identificar los desaparecidos y conocer la verdad de los hechos, sino la creación de los Centros de Memoria. Se equipara allí, el Derecho a la Memoria con el derecho a la verdad, afirmando que:

La memoria histórica de las víctimas del conflicto colombiano desaparecidas forzadamente será objeto de conmemoración la última semana de mayo, en el marco de la Semana de los Detenidos - Desaparecidos, y el treinta (30) de agosto, Día Internacional de los Desaparecidos.

Los establecimientos educativos públicos y privados y las autoridades nacionales, departamentales y municipales rendirán homenaje a estas víctimas esta semana con la realización de foros, conferencias, talleres y jornadas de reflexión referentes al derecho a la memoria, a la verdad, a la vida y al respeto por los derechos humano (Congreso de la República de Colombia, 2010, Artículo 14).

En el 2010, se instituye en Colombia el asunto de la memoria como un derecho y se promulgan la Ley 1408, que rinde homenaje a las víctimas del delito de desaparición forzada, y antecede a la Ley 1448 de 2011. Esta última ubica el Derecho a la Memoria en relación a la satisfacción de las víctimas y pone el asunto de la memoria en el plano jurídico. A partir de allí, puede pensarse entonces desde el Derecho lo que se ha denominado universalmente como Derecho a la Memoria.

En el 2011, con la Ley 1448, se ubican entonces disposiciones que, en relación al Derecho a la Memoria, intentan satisfacerlo desde lo que se establecen como posibilidades de reparación simbólica a las víctimas. El 
capítulo IX de la mentada Ley es la única parte de la misma en la que se ubican disposiciones referentes a la memoria y sólo aparecen en relación a la posibilidad de reparación simbólica de las víctimas. Así, afirma la Ley 1448:

Se entiende por reparación simbólica toda prestación realizada a favor de las víctimas o de la comunidad en general que tienda a asegurar la preservación de la memoria histórica, la no repetición de los hechos victimizantes, la aceptación pública de los hechos, la solicitud de perdón público y el restablecimiento de la dignidad de las víctimas (Congreso de la República de Colombia, 2011, artículo 141).

Lo anterior indica que, así pensado, el Derecho a la Memoria estaría inexorablemente ligado a la reparación y satisfaría las dimensiones individuales del mismo. Esto se deja entrever nuevamente en el capítulo $X$ de la Ley 1448, cuando contempla las "garantías de no repetición". Sin embargo, no se estipula como garantía ningún acápite en relación a la preservación de la memoria y la lucha contra el olvido.

El capítulo X de la Ley 1448, que se divide en dos artículos, propone entonces que el Estado implementará algunas medidas para que los actos violentos no se repitan (Congreso de la República de Colombia, 2011). En el artículo 149 de dicha Ley, se enumeran 19 medidas sin detallar como se ejecutarán, pero que pretenden incluirse en planes, programas y proyectos que, dentro de la política pública, se erijan como garantías de no repetición. En el artículo inmediatamente siguiente, el 150, se propone, sin decir cómo se realizará, el “desmantelamiento de las estructuras económicas y políticas" de los grupos al margen de la Ley. Así reza el artículo:

El Estado Colombiano adoptará las medidas conducentes a lograr el desmantelamiento de las estructuras económicas y políticas que se han beneficiado y que han dado sustento a los grupos armados al margen de la ley, con el fin de asegurar la realización de las garantías de no repetición (Ley 1448, Congreso de la República de Colombia, 2011, artículo 150).

Resulta interesante anotar que en el capítulo que la Ley 1448, donde se describe lo que el Estado concibe como garantías de no repetición, no se contempla el asunto del Derecho a la Memoria como una medida y un fin alcanzable; sólo aparece mencionado en relación a la posibilidad de reparación simbólica. Pensado así, el Derecho a la Memoria estaría en el orden de la individualidad, pues la reparación simbólica de las víctimas encontraría lugar en la singularidad. Sin embargo, al no aparecer descrita en la Ley 1448 la forma como se implementarán estas medidas, puede resultar confuso lo que se pretende alcanzar, a saber, el Derecho a la Memoria como fin singular de una y cada una de las víctimas y su relación con la reparación de las mismas; así como también el Derecho a la Memoria como fin colectivo y su relación con las garantías de no repetición de los actos violentos, que es lo que se entiende como memoria histórica.

La Ley 1448 propone algunas medidas para la preservación del olvido en el marco del Derecho a la Memoria. Se consagra el 9 de abril de cada año como día nacional de conmemoración, "Día de la Memoria y 
Solidaridad con las Víctimas", así como también se instituye la creación del Centro de Memoria, cuyo fin es "reunir y recuperar todo el material documental, testimonios orales, entre otros, relativos a las infracciones al Derecho Internacional Humanitario y violaciones de los derechos humanos" (Uprimny y Saffonm, 2005, p. 139). Sin embargo, no es menos cierto que estas implementaciones, aunque dan cuenta de lo vivido toda vez que ellas recogen testimonios de las víctimas, puede parecer que no están orientadas a la reparación del daño, sino a que se conozca la historia con el fin de evitar la repetición de los hechos violentos. Es decir que esto, así pensado, no viabiliza la reparación, como se ha planteado en la Ley 1448 , sino que parece dejar por fuera al sujeto en su singularidad y apunta más bien al asunto de la memoria como algo colectivo, es decir, a la memoria histórica. Se trata así de un intento que busca que el pueblo conozca los hechos y la historia del conflicto armado colombiano, lo que empieza a dejar un poco de lado el asunto de la reparación.

Con el Decreto 2244 del año 2011 se agregan otras funciones al Centro de Memoria Histórica que parecen complejizar las funciones de dicho ente, así como su operatividad, pues le otorgan, dentro del marco de la Ley de Justicia y Paz, el carácter de "mecanismo no judicial de contribución a la verdad y la memoria histórica" (Presidencia de la República de Colombia, Decreto 2244, 2011, p.2). Aparece entonces el Centro de Memoria Histórica como operador no judicial que contribuye a la preservación de la memoria histórica y el esclarecimiento de la verdad de los actos violentos cometidos dentro del conflicto armado.
Lo anterior parece indicar que, para la Ley, la creación del Centro de Memoria Histórica, así como la difusión y el relato de los actos violentos, se iguala a la reparación de las víctimas, lo que dejaría por fuera las posibilidades de los sujetos de ir a las instancias judiciales, donde los hechos sean revisados uno por uno, caso por caso y se dé lugar a la implementación de acciones de reparación simbólica que apunten también a lo individual, al sujeto en su particularidad y propendan por la preservación de la memoria de cada uno.

Así, la llamada Ley de Víctimas (Ley 1448 de 2011), establece que el derecho a la reparación simbólica, que incluye el Derecho a la Memoria, pertenece al plano de lo social, afirmando que:

Las personas que hayan sido víctimas por hechos ocurridos antes del $1^{\circ}$ de enero de 1985 tienen derecho a la verdad, medidas de reparación simbólica y a las garantías de no repetición previstas en la presente ley, como parte del conglomerado social y sin necesidad de que sean individualizadas (Congreso de la República de Colombia, 2011, artículo 3, parágrafo 4, p. 1)

Esto implica que el Derecho a la Memoria hace parte del entramado social, toda vez que es la sociedad como conglomerado quien puede exigir conocer la verdad de los hechos violentos dentro del conflicto armado, así como la implementación de medidas para la no repetición y las medidas para la posible reparación simbólica. Es decir, la reparación simbólica que pretende la Ley aparece como acciones realizadas a favor de 
las víctimas o de la comunidad en general que tiendan a asegurar la preservación de la memoria histórica, la no repetición de los hechos victimizantes, la aceptación pública de los hechos, la solicitud de perdón público y el restablecimiento de la dignidad de las víctimas (Congreso de la República de Colombia, 2011, p. 44)

Al colocar el Derecho a la Memoria, en el plano de lo social, de la comunidad, este aparece como un derecho para toda la sociedad en general, donde puede ser olvidado el sujeto en su singularidad y el Derecho a la Memoria individual. Por tanto, para poder bordear las posibilidades de reparación simbólica en el postconflicto armado colombiano, ambas condiciones (lo social y lo individual) se hacen importantes y necesarias.

\section{Memoria y Olvido en Psicoanálisis}

El Psicoanálisis siempre se ha interesado por los procesos psíquicos que atañen al ser humano. Estos incluyen la forma como se establece el lazo social, la violencia y los efectos que ella deja en los sujetos y en la cultura. A partir de allí, puede pensarse que la vivencia de la guerra trae consigo secuelas en la cultura y en la subjetividad de quienes la padecieron (Freud, 1919a). Estos efectos que suelen ser generalmente traumáticos, con frecuencia aparecen acompañados de la dificultad por parte de los sujetos afectados para olvidarlos. Por tanto, la memoria los tiene presentes permanentemente, no puede vaciarse del pensamiento de los eventos traumáticos para que estos sean enviados al olvido y puedan ser retrotraídos a la memoria nuevamente, por medio del recuerdo.
La memoria y el olvido son procesos cuya complejidad demanda trascender el habitual reduccionismo cognitivo, que les equipara como procesos mecánicos del organismo. Se sabe que tales procesos integran la constitución de un aparato psíquico que abarca una serie de inscripciones permanentes llamadas "huellas mnémicas" (Cosentino, 1999). Cabe resaltar que "la función atinente a esa "huella mnémica" la llamamos memoria" (Freud, 1900, p. 673). La memoria, como función a la vez constitucional de la vida psíquica del ser humano, demuestra su correspondencia con la subjetividad en el uno por uno de los casos clínicos (Coblence, 2003; Cosentino, 1999; Merea, 1994). Ahora bien, para comprender de mejor manera este asunto funcional y constitutivo de la memoria, a partir de la inscripción perenne que cumple la "huella mnémica", hay que destacar el valor del olvido para el sujeto que, de manera también constitucional, corresponde a la impresión que han dejado consigo las experiencias que parten desde la vida infantil (Freud, 1901) y que permanecen perdurables y reprimidas para la conciencia a lo largo de la vida.

El asunto de la memoria y las posibilidades de olvido para un sujeto son algo que ha ocupado al Psicoanálisis desde los primeros años del desarrollo freudiano. Ya en 1895, Sigmund Freud, en "Proyecto de una psicología para neurólogos" (p. 209), afirma que:

Una de las características principales del tejido nervioso es la memoria, es decir, en términos muy generales, la capacidad de ser permanentemente modificado por procesos únicos, característica que contrasta tan notablemente con la conducta de una materia que deja pasar un movimiento ondulatorio, 
para retornar luego a su estado previo. Toda teoría psicológica digna de alguna consideración habrá de ofrecer una explicación de la "memoria" (Freud, 1895, p.214).

Si Freud se interesa tanto en descubrir y describir cómo funciona el aparato psíquico, en el que incluye la conciencia y la memoria es porque intuye que este y su funcionamiento no pueden pensarse lejos de los procesos anímicos propios del ser humano, sino que hay entre ellos una estrecha relación en la que, aunque Freud establece que no es lo mismo el aparato psíquico que el cerebro, no puede pensarse que este aparato queda reducido al funcionamiento cerebral.

Aunque, Freud (1895) construye su teoría del aparato psíquico apoyado en interrogantes sobre el funcionamiento del cerebro y de algunas funciones como la memoria, la teoría que construye va mucho más allá del modelo orgánico y la pregunta por cómo el inconsciente inscribe las vivencias, que luego son posibles recordar para un sujeto, transforma el asunto de la memoria en un concepto propio del Psicoanálisis. Escribe a Wilhelm Fliess:

Como sabes estoy trabajando sobre la presunción de que nuestro aparato psíquico sea originado por un proceso de estratificación: el material existente en la forma de rastros mnemónicos experimentaría de tanto en tanto un reordenamiento de acuerdo con nuevas relaciones, en cierto modo una transcripción. Así, lo esencialmente nuevo en mi teoría es la afirmación de que la memoria no se encuentra en una versión única, sino en varias, o sea, que se haya transcrita en distintas clases de signos (Freud, 1896a, p. 3551).

Lo anterior implica que la memoria, para el Psicoanálisis, se entiende como un concepto complejo que permite de manera multimodal para el ser humano inscribir en el inconsciente los eventos vividos, así estos, como se sabe desde los planteamientos que hiciera Freud, no hayan sido efectivamente una realidad, sino que basta con que se hayan vivenciado en el inconsciente para que un sujeto los registre como algo que efectivamente sucedió (Fernández, 2001; Giménez, 1999). Esta postura, que rebate el asunto del trauma como idea universal que abre paso a lo sintomático, también pone los primeros escalones para que Freud (1896b) piense la "etiología de las neurosis" (p. 277), pues si bien algunos relatos de algunos pacientes lograban constatarse, no es menos cierto, que, en la mayoría de los historiales clínicos freudianos, no coincidía lo ocurrido realmente con lo que cada paciente narraba de ese evento. Es por ello que Freud (1896b) postula a la infancia como el centro de la etiología de las neurosis pues es algo que todo ser humano atraviesa. Es decir, para resolver lo sintomático y aquello que se le repite con insistencia al ser humano, habría que buscar las causas, casi siempre, en la historia infantil.

Así, Freud empieza entonces a trabajar con los datos fantaseados que referían cada uno de los sujetos, a los que se les convocaba para empezar a hablar invocando la regla por excelencia del Psicoanálisis, a saber, la asociación libre, con los límites que imponía el recuerdo. Si bien los pacientes recordaban y esto implicaba cambios en la sintomatología, no era menos cierto que 
también los límites del recuerdo ubicaban a los analizantes en la repetición. Así, llega a afirmar Freud (1914): "el analizado no recuerda nada de lo olvidado o reprimido, sino que lo vive de nuevo. No lo reproduce como recuerdo, sino como acto; lo repite sin saber, naturalmente, que lo repite" (p. 1684).

Es esta repetición que insiste en el humano lo que lleva al Psicoanálisis a plantear la importancia de la resignificación de lo vivido por un sujeto, entendida como reorganizar psíquicamente las experiencias vividas $\mathrm{y}$ ello, plantea el Psicoanálisis, sólo será posible por medio de la palabra y la reorganización de los significantes para así devenir posteriormente en acto, es decir, cesar la repetición (Lacan, 1953). Freud sostiene lo mismo cuando afirma que "nadie puede ser ajusticiado in absentia o in efigie" (Freud, 1912, p. 1653), indicando que, para sanar el pasado, se debe acudir del lado del sujeto, a un proceso de memoria que implica retrotraer lo que se creía olvidado, para posteriormente organizarlo de una manera psíquica diferente y volverlo a olvidar ahora advertido frente a la posibilidad y las razones de la repetición.

Según propone el Psicoanálisis, los eventos que sean posibles recordar para un sujeto estarán velados y podrán ser traídos a la memoria de forma desdibujada gracias al trabajo de defensa y a la instalación de la transferencia en la terapia, condiciones que permitirán que la memoria emerja haciendo gala de un pasado del sujeto que ahora se hace escuchar. Si bien no es posible recuperar el pasado desde lo real, la asociación libre propuesta sí permite bordear ese pasado para obtener efectos simbólicos en la vida del sujeto por medio de las palabras.
Cuando ese "que habla y oye" (Lacan, 1958, p. 727) trae a la memoria lo que suponía olvidado "algo cuenta, es contado, y en ese contado ya está el contador. Sólo después el sujeto ha de reconocerse a sí mismo como el contador" (Lacan 1964, p. 28).

Lo anterior implica que traer a la memoria lo que permanecía reprimido le otorga a un sujeto la posibilidad de reconstruir la historia, a partir de allí, desde otro lugar, uno que le permita el acto desde la advertencia de la posibilidad de la repetición y que, a su vez, en tanto que habla y narra, se modifica él mismo con su narración (Lacan, 1958). La represión entonces opera como mecanismo clave para el proceso de memoria que permite para el sujeto el registro y la huella de su propia historia, que se podrá recordar después, así sea como plantea Freud (1899), de manera encubridora. Postulando posteriormente que:

Los recuerdos infantiles de los hombres no tienen a veces otro origen. En lugar de reproducirse a partir del momento en que quedan impresos, como sucede en los recuerdos conscientes de la edad adulta, son evocados al cabo de mucho tiempo, cuando la infancia ha pasado ya, y aparecen entonces deformados, falseados, y puestos al servicio de tendencias ulteriores, de manera que no resultan estrictamente diferenciables de las fantasías (Freud, 1910, p. 1589).

Desde lo anterior, se entiende que, en la obra freudiana, el recuerdo y lo recordado aparecen como aquello que vela lo reprimido (Freud, 1899) y aunque algo de eso se deja ver con el recuerdo, otro tanto se le escapa al sujeto y le hace difícil la lectura de lo recordado. Tal como cien años después 
de tal texto y en consonancia con él, postula Derrida (1989) "la huella como memoria no es un abrirse paso puro que siempre podría recuperarse como presencia simple, es la diferencia incapturable e invisible entre los actos de abrirse-paso" (p. 277). Esto habla de la flexibilidad de la memoria y de lo que ella implica, es decir, de la posibilidad del olvido. Se trata de un transitar entre recuerdos que velan o bien algo pasado muy primario de la historia de un sujeto o bien algo posterior a los recuerdos primarios.

De esta posterioridad también se ocuparía más tarde el psicoanalista francés Jacques Lacan, quien a partir de las lecturas de la obra freudiana retoma el concepto de Nachträglichkeit, que había postulado anteriormente Freud y que ha sido traducido del alemán al castellano como "retroactividad" (Laplanche y Pontalis, 1968, p. 280). Este implica que, para el inconsciente, los efectos de una experiencia subjetiva no guardan relación con la cronología, sino que por el contrario ellos pueden permanecer en la temporalidad y detenidos en el inconsciente durante mucho tiempo.

Esta retroactividad implica para el Psicoanálisis que es posible, para un sujeto, concebir el pasado de una manera diferente, siempre que él mismo pueda colocarse desde otro lugar, toda vez que logre resignificar los acontecimientos. Ello permite que el sujeto encuentre un nuevo sentido a los sucesos vividos; así los recuerdos pasados pueden entonces empezar a significar un sinnúmero de cosas que permitan al sujeto reescribir la vida y elaborar nuevos modos de respuesta atravesadas ahora por lo simbólico, es decir las palabras que marcan y atraviesan su historia. De ello, dice Fanny Blanck-Cereijido:
De este modo el sujeto reinscribe constantemente su historia vital y la reinterpreta a la luz de los nuevos sentidos que puede ir elaborando. Esto nos indica que la memoria no es un depósito inmóvil de huellas mnémicas, sino que cada trayecto vital, cada conocimiento nuevo que obtiene sobre sí mismo va modificando el carácter de las huellas y su sentido constitutivo. Cada vivencia que arroja luz sobre el presente se proyecta hacia el pasado, y el presente se puede constituir como causa de un pasado diferente, que a su vez crea una diferente posibilidad de futuro (Blanck-Cereijido, 2006, p. 58).

Así, la historia que se devela para un sujeto cada vez que aparece un recuerdo es una historia velada, encubridora (Freud, 1901), una historia que muestra otra cosa, que deja escapar algo en relación al deseo del sujeto y también eso que el Psicoanálisis denomina como fantasma ${ }^{4}$. Esto implica que, al volver un sujeto a reconstruir su historia por medio de la memoria y el tejido simbólico que haga de sus recuerdos, hay paralelamente una deconstrucción de esa misma historia que se devela encubierta y que remite al sujeto a lo más íntimo de su verdad y de sus deseos, comprometido así con el lenguaje que lo marca y le hace único antes de nacer.

Esa nueva construcción posible para un sujeto, por medio de la terapia analítica, es la que produce un efecto en las formas de responder frente a la vida, una que permita la no repetición. Entender ese pasado que

4 El concepto de Fantasma ocupa un lugar central en la enseñanza de Lacan, quien, a partir de 1957, lo construye como un concepto en relación a "la respuesta del sujeto al deseo enigmático del Otro, un modo de hacer la pregunta sobre qué es lo que quiere el Otro de mi" (Evans, 1996, p.91) 
en principio aparece en el olvido permite al sujeto construir un presente desde otra posición, lo que a su vez puede abrir posibilidades de un futuro distinto, uno donde el sujeto pueda advertirse responsable del lugar que ocupa dentro de su propia historia y en la construcción de sus propios síntomas.

El Psicoanálisis, se ofrece entonces en su trabajo con el sujeto, como una "erotología del olvido" (Allouch, 1999, p. 7), que advierte al sujeto que, para olvidar y construir una historia diferente, resignificada, es necesario recordar, hacer gala de la memoria. Esto, paradójicamente, permite al ser humano percatarse de la presencia de algo que falta, que, por decir así, se trata de algo ausente para la conciencia, del olvido, ese que a su vez resiste desaparecer dada su presencia en el inconsciente.

\section{Conclusiones}

La coyuntura histórica y social que atraviesa Colombia sobre el postconflicto nacional promueve el interés de reflexionar el lugar de la memoria como factor decisivo en los procesos de reparación, más aún en el papel que ésta cumple de manera estructural, cuando se trata del sujeto, que de modo singular padece la experiencia del conflicto armado. Ese sujeto que precisamente con su palabra puede dar cuenta, en la clínica y también en los estrados judiciales, que jamás olvida y que en tanto los recuerdos y la huella mnémica de lo vivido insisten en la memoria, puede decirse que él ha fijado sobre estos acontecimientos su subjetividad.

Esos recuerdos y esa huella mnémica, de la que no es posible escapar para un sujeto $y$ que puede retrotraerse por medio de procesos de memoria y aislarse por medio de procesos de olvido, han interesado desde siempre a ciencias que se ocupan de interrogantes sobre el humano y la búsqueda del ser. En este sentido, ni el Derecho ni el Psicoanálisis han sido ajenos a tal situación, toda vez que ambos tienen como eje al sujeto, bien sea al sujeto jurídico o aquel que está referido al inconsciente. También, ambas disciplinas, tanto el Derecho como el Psicoanálisis, hacen una lectura de la cultura, puesto que el sujeto en el que se centra su cuestión está necesariamente inmerso en ella.

Si bien la memoria se inscribe como algo que es posible retrotraer al plano de lo consciente, también opera como aquella que en ocasiones bloquea el recuerdo. Memoria y olvido son procesos que aparecen llevados de la mano cuando del sujeto se trata, sea éste el sujeto jurídico referido a la Ley y/o el sujeto como lo propone el Psicoanálisis, es decir, el sujeto gobernado por el inconsciente, lugar desde donde operan los procesos de memoria y olvido.

El Derecho a la Memoria es propuesto a partir de los procesos de postconflicto armado y violaciones a los Derechos Humanos y se inscribe dentro del marco normativo del Derecho, entendido como aquel que "no sólo es técnica sino también cultura" (Luther, 2010, p. 47). Por ello, se ocupa de los sujetos inmersos en esa cultura que, si bien no pueden ser prisioneros de la memoria que les antecede en tanto memoria histórica, tampoco se debe desconocer, pues tal como lo planteó Jorge Santayana "quienes no pueden recordar el pasado están condenados a repetirlo" (como se citó en González, 2010, p. 59).

Lo anterior implica que aunque es posible para el sujeto servirse de los procesos de 
memoria y olvido para hacer avanzar su historia, no es menos cierto que tratar de aislar y desconocer esa historia trae consigo consecuencias que están en el orden de la repetición incesante, por medio del proceso inherente a la memoria, es decir, el olvido. Así, esa repetición puede regresar con mayor fuerza para aquellos pueblos que tienen una historia marcada por hechos violentos, frente a los cuales se espera, desde el Derecho, que operen los procesos de memoria y olvido para dar paso a la justicia.

Así, insistir en un Derecho a la Memoria histórica como parte fundamental de los procesos de Justicia Transicional, en toda nación que intenta, como Colombia, cesar el conflicto armado interno, implica entender que si bien no se trata de aceptar sin excepción todas las condiciones solicitadas por las partes que instan acordar el cese de la violencia, este derecho sí aparece, como indica Millard (2014), como aquel que "permitirá más eficazmente la transición y el establecimiento duradero de la democracia y del respeto de los derechos humanos"' (p. 155).

Lo anterior indica que, si bien la memoria y el marco del Derecho en el que ella se inscribe se encuentran en relación con la historia y con los hechos violentos ocurridos, es precisamente esta historia con sus hechos la que permite elaborar el Derecho a la Memoria. Es lo que se recuerda y lo que se retiene de esa historia lo que construye y constituye la memoria histórica de una sociedad. Es en beneficio de conseguir la construcción de la memoria histórica como un Derecho para los nacionales que, en Colombia, la llamada Ley de Víctimas (Ley 1408 de 2010) llega a obligar al Estado a propender no sólo por el conocimiento de la verdad sino también por fechar eventos que permitan dicha construcción, así como también a instituir lugares físicos que posibiliten, desde lo simbólico, bordear esa construcción. Es por ello que la Ley 1408 dispone que, para lograr el Derecho a la Memoria, "en aquellos lugares que se declaren como Santuario de la Memoria, se erigirá, por parte de las autoridades nacionales, un monumento en honor a estas víctimas, para lo cual podrán incluir la respectiva apropiación presupuestal" (Art. 12). La memoria aparece entonces, dentro del marco legal, no sólo como un derecho reglamentado al que el sujeto puede acceder, sino también como aquello que para instituirlo es necesario establecer cuestiones simbólicas que permitan tal labor. Es decir, las fechas, los monumentos, etc., permiten a la población nacional bordear lo horroroso de la guerra, dando lugar a que ella se inscriba como recuerdo perenne. Si bien no se trata de permanecer en la guerra, sí se intenta reconocer y nombrar, de esta manera, parte de lo que allí ocurrió.

Es claro que el sistema jurídico reclama y reconoce como derecho el lugar de la memoria para los pueblos que han sufrido la guerra, pues el Derecho en tanto disciplina no sólo se ocupa de los efectos penales que trae dicha guerra, sino que intenta, dentro de sus pilares, buscar un lugar a la paz. El Derecho internacional se entiende así, como aquel que permite sortear el lugar de la guerra y dar paso a la sana convivencia, a la paz (García, 2013, p. 145). Sobre ello, enseña el austriaco Hans Kelsen, que, para conseguir la paz, es necesario no sólo que el derecho colectivo prime sobre el individual, además afirma:

Uno de los medios más eficaces para impedir la guerra y garantizar la paz internacional es la promulgación de 
reglas que establezcan la responsabilidad individual de las personas que como miembros del gobierno han violado el Derecho Internacional recurriendo o provocando la guerra (Kelsen, 1953, p.91).

Lo anterior indica que para Kelsen (1953) resulta posible pensar en el progreso de una nación, siempre que la Ley y su reglamentación no se sustraigan del asunto de la paz. Si, en cambio, las naciones insisten en la guerra, debe entenderse que esta decisión acarrea una responsabilidad colectiva en la que posteriormente se hacen evidentes no sólo sus estragos, sino también la necesidad del Derecho Internacional. De este emerge la justicia como un orden social en el que Kelsen (1944) reconoce implícita la presencia del conflicto pues apunta: "ningún orden social puede solucionar de manera justa el problema que la felicidad de uno provoca irremediablemente la desgracia de otro" (p. 23). Es allí donde el asunto de la memoria y la construcción de ella y de la historia tienen también asiento.

El Psicoanálisis por su parte ha indicado que no es posible domeñar los procesos psíquicos (huellas mnémicas, pulsiones, fantasías, etc.) y son ellos los que, en buena parte, definen al ser humano de manera singular. Esta idea coloca de plano que el derecho que tienen las victimas a la reparación, amparado en el marco jurídico para el que se propone la importancia de la construcción de la memoria histórica, tiene a su vez otro tipo de repercusiones que trascienden a las normas y la ley. Sobre esto hay que plantear que el impacto subjetivo que trae consigo el horror de la guerra implica que es necesario abordar, en el caso por caso, la manera en que el sujeto ha inscrito con su padecer este tipo experiencias. Desde este punto de vista es posible comprender la vida psíquica más allá de la conciencia, que nos hace creer en la posibilidad de totalizar la responsabilidad subjetiva de modo moral, que armoniza, por ejemplo, con los preceptos del bien hacer que impone una sociedad. Tal añoranza, "sería imposible, pues en cuanto hay psique, hay transgresión" (Castoriadis, 2004, pp. 183-184). Esto indica que fenómenos como el de la violencia pueden ser interrogados en relación con la participación que cumple ahí definitivamente la vida psíquica del ser humano; en otros términos, su implicación subjetiva.

Es decir, el sujeto como lo propone el Psicoanálisis responde de diversas maneras frente a lo que vive y cómo esa historia que vive deja su impronta en la vida psíquica. La subjetividad, como indica Castoriadis (2004), no obedece a "la realización de la voluntad dividida, el cumplimiento de las leyes de la historia o del destino de la raza, etc., sino la obra determinada por la actividad de los seres humanos, actividad en la cual participa él mismo" (p. 191). Si bien el sujeto es determinante de su propia historia, esa historia también determina al sujeto y la forma como este se coloca frente a la vida con lo que sabe propio, a saber, los recuerdos, el olvido, las fantasías y aquello que constituye lo psíquico.

Entonces, en el trabajo psicoanalítico no se trata en definitiva de la historia arqueológica, fechable, cronológica de un sujeto. Tal trabajo ofrece al sujeto la posibilidad de operar sobre su propio inconsciente, ese que desde Freud (1940) se sabe que es atemporal, ausente de contradicción. Es 
justamente por esas particularidades que la intervención sobre ese inconsciente que emerge en el análisis tiene efecto en la historia por venir de un sujeto. Si bien no se pueden dominar los procesos psíquicos, sí se puede operar sobre el lugar desde el que ellos se hacen escuchar. Desde allí, entonces, se hace posible no sólo que los recuerdos emerjan, sino que esos recuerdos retrotraídos del olvido que constituyen la memoria se asuman desde un lugar que permite su resignificación y una historización diferente, es decir, una construcción distinta, en la que el sujeto se reconoce y simboliza su historia. "Si un trabajo analítico es posible, es porque el sujeto y el analista piensan que la exploración del pasado permite la apertura del porvenir" (Baranger, Baranger \& Mon, 2002, p. 121).

Lo anterior pone en evidencia que si bien es cierto que se pueden olvidar apartes de la historia, no es menos cierto que ese olvido aparece sólo como un telón que vela todo aquello que puede retrotraerse a los recuerdos más íntimos. En tanto posee esta condición, es viable entonces un trabajo de nueva construcción de memoria. El Derecho intenta alcanzar dicha nueva construcción desde la Ley: el asunto de la memoria se propone como un derecho enmarcado en la misma. En el Psicoanálisis tal cuestión de memoria y el olvido estaría del lado de aquello por lo que el sujeto puede hacerse también responsable, en tanto es posible para él preguntarse por eso y en tanto es el mismo sujeto el depositario de los recuerdos, aunque ellos, como postula Freud (1915), "se hallan fuera de tiempo; esto es, no aparecen ordenados cronológicamente, no sufren modificación ninguna por el transcurso del tiempo y carecen de toda relación con él" (p. 2073). Pese a ello, es el sujeto no sólo el dueño de esos recuerdos, sino también el protagonista de su historia, así ella aparezca a la manera que postula el Mannoni (1998) “de un saber que no se sabe" (p. 1).

Lo anterior pone de plano que el trabajo de memoria es una posibilidad a la que le apuestan tanto el Psicoanálisis como el Derecho y ambas disciplinas no son ajenas a la importancia del Otro. El Derecho lo invoca del lado de la justicia, escenario en el que aparecen los que hacen posible operar la Ley, a saber, jueces, testigos, etc., que emergen dando cuenta que el proceso de construcción de memoria para hacerse viable no puede ser ajeno al conocimiento de la verdad de los hechos y al establecimiento y construcción de fechas y lugares que rindan culto a los horrores vividos por la guerra y que permitan no olvidar. El Psicoanálisis por su parte, da cuenta de la importancia del Otro cuando señala que ese conocimiento de la verdad acerca de la guerra permite la solidaridad de un duelo que puede hacerse ahora con el acompañamiento del Otro como testigo. Tal como apunta Allouch (2011), esto hace posible subjetivar la pérdida, es decir, poder perder lo perdido para que ello no retorne como apunta Freud (1919b) de modo siniestro, sin poderse evitar pues está en el orden de "la repetición involuntaria" (p. 2495).

Recordar es un modo entonces de posibilitar las pérdidas, de nombrar los horrores vividos en y por la guerra. Ofrecer a la población un trabajo de construcción de memoria histórica, implica reconocer que "el olvido trabaja en la memoria, es su componente y está presente en el recuerdo" (Escobar, 2015, p. 365). Así planteado, no se puede desconocer la importancia del Otro, ni tampoco 
los procesos psíquicos que atañen a la posibilidad de la construcción de esa memoria, pues ellos son inherentes a esa contingencia. Olvido y memoria van de la mano y demandan que los horrores de la guerra y sus estragos sean dichos y conocidos. Esto permite que tanto olvido como memoria ejerzan su función, es decir posibiliten una vía simbólica a lo acontecido en lo real. Para que se pueda agujerear ese real es necesario que el sujeto hable y así tejer la posibilidad de la memoria histórica, pues de lo contrario, como señala Lacan (1954), ocurriría que "aquello de lo que el sujeto no puede hablar, lo grita por todos los poros de su ser" (p. 367). Poder hablar de lo acontecido, permite hacer un tejido simbólico que "cristaliza la memoria social" (Ortega, 2004, p. 104). Si bien el postconflicto armado colombiano no finiquita con la firma de los acuerdos posibles ni tampoco con las Leyes creadas para tal fin, estas si aparecen como un intento por un inicio desde un lugar diferente, un lugar nuevo que permita al pueblo colombiano no sólo enmarcar la guerra dentro de la Ley, sino también, con la institución de ritos simbólicos acerca de lo vivido (monumentos, centro de memoria histórica, fecha de calendario de día de la memoria), bordear lo espantoso de lo real y construir una memoria histórica a partir de una significación diferente, con la que el sujeto pueda reconocer, no solo su protagonismo social, sino además, su participación subjetiva.

\section{REFERENCIAS}

Allouch, J. (1999). El sexo de la verdade: erotología analítica II. Córdoba: Ediciones de la École Lacaniana de Psychanalyse.
Allouch, J. (2011). Erótica del duelo en tiempos de la muerte seca. Buenos Aires: Cuenco de Plata.

Barenger, M., Barenger \& Mon, J. (2012, septiembre). Proceso y no proceso en el trabajo analítico. Revista Psicoanalítica Argentina, $39 \mathrm{~N}^{\circ} 4$, pp. 114-131.

Blanck-Cerejido, F. (2006). La memoria en el diván. Acta Poética, 27 (2), pp. 43-63

Caso Anzualdo Castro vs. Perú. Sentencia de 2009, septiembre 22. Recuperado de: http://www.corteidh.or.cr/docs/casos/ articulos/seriec_202_esp.pdf

Castoriadis, C. (2004). Sujeto y verdad en el mundo histórico - social. En: La creación humana I. Buenos Aires: Fondo de Cultura Económica

Coblence, F. (2003). Sigmund Freud I 1886 - 1897. Vida y pensamiento psicoanalítico. Madrid: Biblioteca Nueva.

Cosentino, J. (1999). Construcción de los conceptos freudianos I. Defensa, sueño, aparato psíquico. Buenos Aires. Ediciones Manantial.

De Greiff, P. (2005). El deber de recordar iel peso muerto del pasado o el peso de los muertos del pasado?. En: Razones de la justicia. Homenaje a Thomas McCarthy (pp. 191-221). México: UNAM-instituto de Investigaciones Filosóficas.

Decreto 2244. Presidencia de la República de Colombia, Bogotá, Colombia, 28 de junio del 2011

Derrida, J. (1989). Freud y la escena de la escritura. En: La escritura y la diferencia (pp. 271-317). Barcelona: Anthropos.

Escobar, C. (2015, ene/abr). El olvido del olvido: Una aproximación psicoanalítica. Filos, $27 \mathrm{~N}^{\circ} 40$, pp. 345-373. Doi: 10.7213/ aurora.27.040.A005 
Evans, D. (1996). Diccionario Introductorio de Psicoanálisis Lacaniano. Buenos Aires: Paidós.

Fernández, M. (2001). Del inconsciente freudiano al significante lacaniano. Medellín: Universidad de Antioquia.

Freud, S. (1895) Proyecto de una psicología para neurólogos. En: Obras Completas Tomo I [1973] (pp. 209-276) Madrid: Biblioteca Nueva.

Freud, S. (1896a). Los Orígenes del Psicoanálisis "Carta 52". En: Obras Completas Tomo III [1973] (pp. 3551) Madrid: Biblioteca Nueva.

Freud, S. (1896b) La herencia y la etiología de las neurosis. En: Obras Completas Tomo I [1973] (pp. 277-285) Madrid: Biblioteca Nueva.

Freud, S. (1899) Los recuerdos encubridores. En: Obras Completas Tomo I [1973] (pp. 330-341) Madrid: Biblioteca Nueva.

Freud, S. (1900) La interpretación de los sueños. En: Obras Completas Tomo I [1973] (pp. 343-720) Madrid: Biblioteca Nueva.

Freud, S. (1901) Psicopatología de la vida cotidiana. En: Obras Completas Tomo I [1973] (pp. 755-911) Madrid: Biblioteca Nueva.

Freud, S. (1904) El método psicoanalítico de Freud. En: Obras Completas Tomo I [1973] (pp. 1003-1006) Madrid: Biblioteca Nueva.

Freud, S. (1910) Un recuerdo infantil de Leonardo Da Vinci En: Obras Completas Tomo II [1973] (pp. 1577-1619) Madrid: Biblioteca Nueva.

Freud, S. (1912) La dinámica de la transferencia. En: Obras Completas Tomo II [1973] (pp. 1648-1653) Madrid: Biblioteca Nueva.

Freud, S. (1914) Recuerdo, repetición y elaboración. En: Obras Completas Tomo II
[1973] (pp. 1683-1688) Madrid: Biblioteca Nueva.

Freud, S. (1915) Lo inconsciente. En: Obras Completas Tomo II [1973] (pp. 2060-2090) Madrid: Biblioteca Nueva.

Freud, S. (1919a) Introducción al simposio sobre las neurosis de guerra. En: Obras Completas Tomo III [1973] (pp. 25422544) Madrid: Biblioteca Nueva.

Freud, S. (1919b) Lo siniestro. En: Obras Completas Tomo III [1973] (pp. 24842505) Madrid: Biblioteca Nueva.

Freud, S. (1929) El malestar en la cultura. En Obras Completas Tomo III [1973] (pp. 3017-3067) Madrid: Biblioteca Nueva.

Freud, S. (1940) Compendio de psicoanálisis. En Obras Completas Tomo III [1973] (pp. 3379-3432) Madrid: Biblioteca Nueva.

García, J. (2013, marzo - agosto). Memoria histórica y aplicación retroactiva de la sanción penal. Algunos fundamentos desde el pacifismo jurídico de Hans Kelsen. Economía - Revista en cultura de legalidad, 4, pp. 139-153

Giménez, J. (1999). Inconsciente y lenguaje. En Salud mental y psicoanálisis (pp. 4958). Buenos Aires: Universitaria de Buenos Aires.

González, A. (2010) Cuánta razón Santayana... cuánta razón. Elementos: Ciencia y cultura de Redalyc, 79, pp. 59-62

González, J. (2005, julio - diciembre). Verdad, justicia, paz y reparación en la mitología penal. A propósito de la Ley 975 de 2005. Estudios Políticos, 27, pp. 45-63

Kelsen, H. (1944) La paz por medio del Derecho [2008] Madrid: Trotta

Kelsen, H. (1953) Que es justicia? [2003] Barcelona: Ariel S.A.

Luther, J. (2010, mayo - agosto). El derecho a la memoria como derecho cultural del 
hombre. Democracia. Revista Española de Derecho Constitucional, 89, pp. 45-79.

Lacan, J. (1953) Función y campo de la palabra y del lenguaje en psicoanálisis. En Escritos 1 [2008] (pp. 227-310) Buenos Aires: Siglo XXI

Lacan, J. (1954) Introducción al comentario de Jean Hyppolite sobre la Verneinung de Freud. En Escritos 1 [2008] (pp. 351362) Buenos Aires: Siglo XXI

Lacan, J. (1958) Juventud de Gide o la letra y el deseo. En Escritos 2 [2013] (pp. 703725) Buenos Aires: Siglo XXI

Lacan, J. (1964). Seminario 11 : Los cuatro conceptos fundamentales del psicoanálisis. Argentina: Editorial Paidós

Laplanche, J \& Pontalis, J. (1968). Diccionario de psicoanálisis. Barcelona: Labor

Laplante, L \& Theidon, K. (2008). Transitional justice in times of conflict: Colombia's Ley de Justicia y Paz. Michigan Journal of International Law, 28:49, pp. 49-60. Recuperado de: http://repository.law.umich.edu/cgi/viewcontent. cgi article $=1158 \&$ context $=$ mjil

Ley 418. Congreso de la República de Colombia, Bogotá, Colombia, 26 de diciembre de 1997.

Ley 782. Congreso de la República de Colombia, Bogotá, Colombia, 23 de diciembre del 2002.

Ley 975. Congreso de la República de Colombia, Bogotá, Colombia, 25 de julio del 2005.

Ley 1408. Congreso de la República de Colombia, Bogotá, Colombia, 20 de agosto del 2010.
Ley 1448. Congreso de la República de Colombia, Bogotá, Colombia, 10 de junio del 2011.

Mannoni, M. (1998) Un saber que no se sabe: La experiencia analítica. Barcelona: Gedisa

Merea, C. (1994) La extensión del psicoanálisis. Buenos Aires: Paidós

Millard, E. (2014, enero - junio). ¿Por qué un derecho a la memoria?. Derecho del Estado, 32, 145-156. Recuperado de: http:// revistas.uexternado.edu.co/index.php/ derest/article/view/3818/4056

Morris, Ch., González, D., Morelo, L \& Palencia, S. (2015) Justicia transicional en Colombia: perdón y justicia en la legislación del conflicto. Avances y desafíos del derecho. Abordaje desde la investigación jurídica y socio jurídica. (pp. 498-508) Cartagena: Alpha Editores - Universidad Libre

Ortega, F. (2004, enero) La ética de la historia: Una imposible memoria de lo que olvida. Desde el jardín de Freud - Revista de psicoanálisis, 4, pp. 102-119

Rincón, T. (2010) Verdad, justicia y reparación. La justicia de la justicia transicional. Bogotá: Universidad del Rosario.

Teitel, R. (2003, septiembre). Genealogía de la justicia transicional. Harvard Human Rights, 16, pp. 69-94

Uprimny, R \& Saffon, M. (2005). Justicia transicional y justicia restaurativa: Tensiones y complementariedades. En Entre el perdón y el paredón, preguntas y dilemas de la justicia transicional (pp. 135144). Bogotá: Uniandes. 